\title{
Molecular Insights into the Physical Adsorption of Amphiphilic Protein PhaF onto Copolyester Surfaces
}

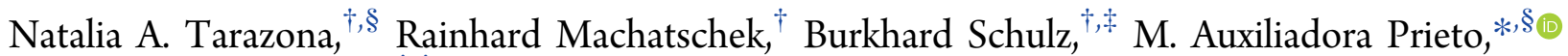 \\ and Andreas Lendlein $*,+\ddagger$ (i)
}

\begin{abstract}
${ }^{\dagger}$ Institute of Biomaterial Science and Berlin-Brandenburg Center for Regenerative Therapies, Helmholtz-Zentrum Geesthacht, Kantstraße 55, 14513 Teltow, Germany

${ }^{\S}$ Department of Microbial and Plant Biotechnology, Centro de Investigaciones Biológicas, CSIC, Ramiro de Maeztu 9, 28040 Madrid, Spain

${ }^{\ddagger}$ Institute of Chemistry, University of Potsdam, Karl-Liebknecht-Straße 24-25, 14469 Potsdam, Germany
\end{abstract}

Supporting Information

ABSTRACT: Phasins are amphiphilic proteins located at the polymer-cytoplasm interface of bacterial polyhydroxyalkanoates (PHA). The immobilization of phasins on biomaterial surfaces is a promising way to enhance the hydrophilicity and supply celldirecting elements in bioinstructing processes. Optimizing the physical adsorption of phasins requires deep insights into molecular processes during polymer-protein interactions to preserve their structural conformation while optimizing surface coverage. Here, the assembly, organization, and stability of phasin

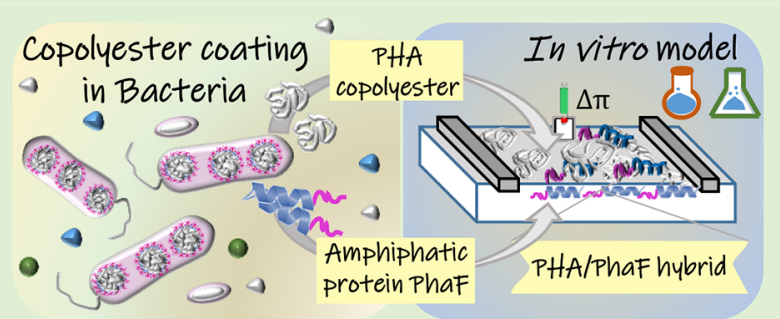
PhaF from Pseudomonas putida at interfaces is disclosed. The Langmuir technique, combined with in situ microscopy and spectroscopic methods, revealed that PhaF forms stable and robust monolayers at different temperatures, with an almost flat orientation of its $\alpha$-helix at the air-water interface. PhaF adsorption onto preformed monolayers of poly[(3-R-hydroxyoctanoate)-co-(3-R-hydroxyhexanoate)] (PHOHHx), yields stable mixed layers below $\pi=\sim 15.7 \mathrm{mN} / \mathrm{m}$. Further insertion induces a molecular reorganization. PHOHHx with strong surface hydrophobicity is a more adequate substrate for PhaF adsorption than the less hydrophobic poly[(rac-lactide)-co-glycolide] (PLGA). The observed orientation of the main axis of the protein in relation to copolyester interfaces ensures the best exposure of the hydrophobic residues, providing a suitable coating strategy for polymer functionalization.

\section{INTRODUCTION}

Multifunctional hybrid materials based on proteins or peptides and synthetic polymers have gained significant interest in material design. ${ }^{1,2}$ For tissue regeneration applications, the immobilization of desired proteins onto scaffolds allows altering the material surface properties for improved biocompatibility and controlled cell-adhesion. Growth factors, therapeutic proteins, extracellular matrix proteins, or the cell binding domains of these proteins have been used for immobilization studies onto scaffolds of varying composition such as poly(L-lactic acid) (PLA), poly( $\varepsilon$-caprolactone) (PCL), and poly[(L-lactide)-co-glycolide] (PLGA). ${ }^{3-5}$

Phasins are low molecular weight, amphiphilic proteins that accumulate at high levels in bacteria dependent on the production of degradable polyhydroxyalkanoate (PHA) polymers. $^{6-8}$ Since PHA assemble as intracellular cytoplasmic inclusions (PHA granules), the main function of phasin proteins is to bind to the polymer-cytoplasm interface of the granules to avoid negative effects of the polyester accumulation on cellular activities and to prevent their coalescence. ${ }^{9-13}$ Although phasins production and location are strictly associated with the PHA granules in bacteria, some phasins were proven to bind to different hydrophobic substrates in vivo and in vitro, including lipid inclusions ${ }^{14}$ and natural or synthetic polymers (e.g., PLA, PLGA, and PCL). ${ }^{15-17}$ In the last years, Chen's group reported the surface modification of PHA by physical adsorption of phasin PhaP (produced by Aeromonas hydrophila). ${ }^{15,17}$ By coating different films with phasin PhaP or PhaP fused to cell binding motifs, e.g. the integrin-binding motif arginine-glycine-aspartic acid (RGD), they succeeded in reducing PHA surface hydrophobicity while promoting attachment and proliferation of different cell lines. ${ }^{15}$ Despite the remarkable properties of phasins, there is still a scarcity of information about their robustness and stability at interfaces and their adsorption behavior, especially to PHA as their natural substrate.

Using physical adsorption, biomaterials can be easily functionalized by immersion into a solution containing the biomolecules that will attach to the material surface owing to

Special Issue: ISBP2018

Received: January 15, 2019

Revised: April 12, 2019

Published: April 16, 2019 
surface interactions, such as van der Waals forces, electrostatic forces, hydrophobic interactions and hydrogen bonds. ${ }^{18}$ Hence, this method allows surface modification while maintaining the bulk polymer properties by using solvent free environments and reducing the damage to the biomolecules. $^{18,19}$ Nonetheless, optimizing the attachment of proteins to polymers via physisorption requires precise control and understanding of polymer-protein interactions to preserve their structural conformation and function. With the Langmuir approach, molecular thin films are formed at the air-water interface (A-W interface), with precise control of the area per molecule and other experimental conditions, allowing the investigation of physical and chemical interactions, at for example membrane surfaces, with a two-dimensional approximation. $^{20-22}$ We hypothesize that this technique can be used with the same success to study the physical adsorption of proteins to prospective biomaterial surfaces, albeit this has rarely been considered.

This paper presents a thorough characterization of the amphiphilic protein $\mathrm{PhaF}$ adsorption onto different interfaces using the Langmuir technique, as a potential toolbox for the surface biofunctionalization of materials. Phasin $\mathrm{PhaF}$, which we recently described as a surface active protein, ${ }^{23}$ is a modular protein with two domains clearly differentiated, and connected by a leucine zipper sequence responsible for its oligomerization (Figure S1). ${ }^{24}$ The PHA-binding domain (N-terminal or BioF) acquires an amphipathic $\alpha$-helix conformation and recognizes the surface of the polymer granule while facing the cytoplasm. The C-terminal domain is highly positively charged, natively unfolded in solution (random coil conformation), and responsible for the binding of PhaF to DNA. The occurrence of a DNA-binding domain is a distinctive characteristic of this protein compared to other phasins. ${ }^{25-27}$ This protein is the most studied phasin in Pseudomonas species accumulating poly[(3-R-hydroxyoctanoate)-co-(3-R-hydroxyhexanoate) $]$ (PHOHHx), a copolyester with low crystallinity, low glass transition temperature, and high elongation to break; suitable for a range of applications in the field of tissue engineering where flexible biomaterials are required. ${ }^{9,28}$ Here, we use $\mathrm{PHOHHx}$ monolayers at the $\mathrm{A}-\mathrm{W}$ interface as a model system to test the interaction between PhaF and its natural substrate as well as for detecting possible alterations in the molecular conformation of both species during a phasin-based functionalization process. The adsorption of PhaF (from the subphase) to the polymer is followed by two in situ methods: Polarization Modulated Infrared Absorption Spectroscopy (PM-IRRAS) and Brewster Angle Microscopy (BAM). The interaction of this protein with a less hydrophobic copolyester, poly[( $\mathrm{rac}-$ lactide)-co-glycolide] (PLGA), ${ }^{29,30}$ will be addressed to substantially improve the understanding on the interplay of polymer hydrophilicity and PhaF adsorption.

\section{MATERIALS AND METHODS}

Phasin PhaF Production and Purification. Overproduction of the PhaF protein, from Pseudomonas putida KT2440, was achieved in recombinant Escherichia coli M15 [pREP4] harboring pQE32-phaF plasmid that allows the production of an $\mathrm{N}$-terminal $\mathrm{His}_{6}$-tagged protein for protein purification. Recombinant $\mathrm{His}_{6}-\mathrm{PhaF}$ was purified by metal ion affinity chromatography (IMAC), using an ÄKTA chromatography system (GE Healthcare Life Sciences), following the

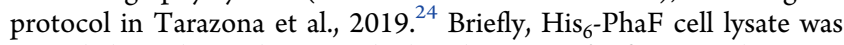
passed through a column packed with $5 \mathrm{~mL}$ of affinity medium NiSepharose (GE Healthcare Life Sciences), equilibrated with buffer containing $20 \mathrm{mM}$ sodium phosphate $\mathrm{pH}$ 7.4, $300 \mathrm{mM} \mathrm{NaCl}, 30 \mathrm{mM}$ imidazole, $0.1 \%$ Triton $\mathrm{X}-100$ and 1 tablet of Roche cOmplete protease inhibitor cocktail per $50 \mathrm{~mL}$ of solution. The column was washed with a three-step gradient of 55,75 , and $125 \mathrm{mM}$ imidazole. A final concentration of $265 \mathrm{mM}$ of imidazole was used to elute $\mathrm{His}_{6}$ PhaF from the column. Purified protein was dialyzed against phosphate buffered saline $140 \mathrm{mM} \mathrm{NaCl}, \mathrm{pH} 7.4$ (PBS), aliquoted, and stored at $-20{ }^{\circ} \mathrm{C}$ for further assays. Prior to use, aliquots were centrifuged $5 \mathrm{~min}$ at $13000 \mathrm{~g}$ to remove aggregates. Protein absorbance was measured in a UV-vis spectrophotometer at $\mathrm{Abs}_{280 \mathrm{~nm}}$ (Agilent). For accurate concentration measurements, absorbance was corrected for scattering contributions using the formula: ${ }^{31}$

$$
\mathrm{Abs}=\mathrm{Abs}_{280 \mathrm{~nm}}-10^{2.5 \times \log \left(\mathrm{Abs}_{320 \mathrm{~nm}}\right)-1.5 \times \log \left(\mathrm{Abs}_{350 \mathrm{~nm}}\right)}
$$

The protein molar concentration $(\mathrm{mol} / \mathrm{L})$ was obtained using $=\frac{\text { Abs }}{\varepsilon 280 \times l}$, where $\varepsilon=\mathrm{PhaF}$ molar extinction coefficient $\left(19480 \mathrm{M}^{-1}\right.$. $\mathrm{cm}^{-1}$ ) and $l$ is the path length $=1$. PhaF purity was analyzed using $12 \%$ SDS-PAGE.

Copolyester Synthesis, Purification and Characterization. PHOHHx (monomer molar ratio 94 and 6\%, respectively), was synthesized by bacterial fermentation at shaken flask level using Pseudomonas putida KT2440 and $15 \mathrm{mM}$ of octanoic acid as carbon source. During mcl-PHAs biosynthesis, fatty acids (substrate) degrade with removal of a $\mathrm{C} 2$ unit in each cycle in the form of acetyl-CoA, in the so-called $\beta$-oxidation cycle. For that reason, $\mathrm{PHOHHx}$ is a copolyester of monomers with two carbon atoms less than the carbon source in the growth culture. ${ }^{32}$ The $\mathrm{PHOHHx}$ production medium and the culture conditions have been described before. ${ }^{33}$ To obtain a polymer with endotoxin units $(\mathrm{EU}) \leq 20 \mathrm{EU} / \mathrm{g}$, in agreement with the endotoxin requirements for biomedical applications, successive steps of PHOHHx extraction with chloroform at $40{ }^{\circ} \mathrm{C}$, filtration and precipitation with cold methanol were performed. Finally, the polymer was dried under vacuum at $40{ }^{\circ} \mathrm{C}$ for $48 \mathrm{~h}^{33}$ The number-average of molecular weight $\left(M_{\mathrm{n}}\right)$ was determined on a multidetector Gel Permeation Chromatography system as reported before, ${ }^{34}$ using chloroform as eluent with a flow rate of $1 \mathrm{~mL} / \mathrm{min}$ at $35^{\circ} \mathrm{C}$, and $0.2 \mathrm{wt} \%$ toluene as internal standard. Polystyrene samples were used for universal calibration. The structural characterization of purified $\mathrm{PHOHHx}$ was carried out by performing nuclear magnetic resonance spectroscopy (NMR). ${ }^{13} \mathrm{C}$ and ${ }^{1} \mathrm{H}$ NMR measurements were performed at $25{ }^{\circ} \mathrm{C}$ in $\mathrm{CDCl}_{3}$ (VWR, 99.8\%) using a Bruker Avance 300 spectrometer $(300 \mathrm{MHz})$. Chemical shifts are referenced against residual solvent signal $\left(7.26\right.$ and $77.0 \mathrm{ppm}$ for ${ }^{1} \mathrm{H}$ and ${ }^{13} \mathrm{C}$, respectively). Spectra were analyzed using the MestReNova software package. The spectra of ${ }^{1} \mathrm{H}$ - and ${ }^{13} \mathrm{C}$ NMR of the purified $\mathrm{PHOHHx}$ and the assignment of the corresponding PHA by comparison with published data ${ }^{35}$ are depicted in Figure S2.

PLGA $\left(M_{\mathrm{n}}: 8370 \mathrm{~g} / \mathrm{mol}\right.$; lactide content $68 \%$ by weight) was synthesized by ring-opening copolymerization of rac-dilactide and diglycolide using 1,8-octanediol as initiator and the catalyst dibutyltin(IV) oxide as catalyst. The protocol for polymer synthesis and characterization is described in Mathew et al., 2015. ${ }^{36}$

Surface Pressure vs Bulk Concentration Isotherms. Protein monolayers on the $\mathrm{A}-\mathrm{W}$ interface can be formed either by spreading of protein solution on the water/buffer surface (Langmuir monolayers) or upon surface adsorption of the protein molecules injected into the subphase (Gibbs monolayers). ${ }^{37-39}$ The surface activity of PhaF in different subphases and the minimal concentration of PhaF for Langmuir and Gibbs isotherms were examined in a polytetrafluoroethylene circular trough with an area of $\sim 63 \mathrm{~cm}^{2}$ and a surface-area/volume ratio of $0.8 \mathrm{~cm}^{-1}$. A PhaF stock solution (0.7 $\mathrm{mg} / \mathrm{mL}$ ) was added (spreaded or injected) in increments into Milli-Q water or PBS buffer with a Hamilton microsyringe. The surface pressure was monitored in real time using a Wilhelmy plate. For each increment, the surface pressure was allowed to reach equilibrium before the measurements. Calculation of the surface excess with the Gibbs equation resulted in unrealistically high values, which is a common observation for proteins. ${ }^{40}$ Therefore, the surface pressure of compression isotherms is given as a function of trough area. Each experiment was performed twice. All presented isotherm data 
correspond to individual experiment data reproducible with a random measurement error of $\sim 5 \%$ concerning the surface pressure or the MMA values for the independently repeated experiments.

Surface Pressure vs Area $(\pi-A)$ and Surface Adsorption Isotherms. $\pi-A$ isotherms of spread monolayers (Langmuir) on PBS were recorded on a polytetrafluoroethylene Langmuir trough ("large" or "medium" trough, KSV NIMA, Finland) equipped with Delrin barriers, for controlling the mean molecular area (MMA), and a level compensation system (KSV LTD, Finland). The system was placed on an active vibration isolation system (halcyonics variobasic 40, Accurion, Germany) within a cabinet. The changes in the surface tension of the $\mathrm{A}-\mathrm{W}$ interface (surface pressure) were monitored by a filter paper-based Wilhelmy plate microbalance and recorded as a function of the trough area. For PHOHHx $\pi-A$ isotherms, a defined amount of polymer solution in chloroform was deposited dropwise onto PBS using a microsyringe (Hamilton Co., Reno, NV, USA). Before an experiment was started, the chloroform was allowed to evaporate for $10 \mathrm{~min}$. The Langmuir layers were laterally compressed at constant compression rates of $10 \mathrm{~mm} / \mathrm{min}$. The MMA for PHOHHx was calculated based on the weight and the molar fraction of the repeating units $(3 \mathrm{HO}$ and $3 \mathrm{HHx})$ and the surface area of the trough during compression. For PhaF $\pi-A$ isotherms, PhaF solution in PBS was spread drop by drop onto the buffer subphase with a Hamilton microsyringe. The final concentration was $0.013 \mu \mathrm{M}$. A total of $10 \mathrm{~min}$ was allowed for the protein to reach equilibrium at the air-buffer interface before compression. PhaF isotherm was obtained by plotting the surface pressure against the trough area. The compression modulus $C_{\mathrm{s}}^{-1}$ was computed using surface pressure isotherms based on: $C_{\mathrm{s}}^{-1}=-A\left(\frac{\delta \pi}{\delta A}\right)$ where $A$ is the area at the given surface pressure $\pi$. A high value means that a monolayer is rigid and densely packed. Adsorption isotherms (Gibbs monolayers) of PhaF were recorded as an increase of the surface pressure, by a Wilhelmy microbalance, as a function of time after injection $\Delta \pi(t)$, without any external mechanical force. The protein was injected into PBS at a final concentration of $0.18 \mu \mathrm{M}$. The surface area-dependent adsorption was evaluated using three different troughs with surface-area/volume ratios of 1.4, 0.8 , and $0.7 \mathrm{~cm}^{-1}$. The temperature of the subphase for PHOHHx and PhaF isotherms was kept constant at $22 \pm 0.5^{\circ} \mathrm{C}$, if not noted differently. $\pi-A$ isotherms were repeated at least two times.

PhaF Adsorption to Polymer Films. The adsorption of PhaF to PHOHHx preformed monolayers was monitored using a constant surface area approach in a circular trough with a lower surface-area/ volume ratio without compression, resulting in an increase of the surface pressure upon protein insertion. $\mathrm{PHOHHx}$ Langmuir monolayers were prepared by spreading the polymer solution dropwise at the air-buffer interface, until the desired initial surface pressure $(12 \mathrm{mN} / \mathrm{m})$ was reached. After $10 \mathrm{~min}$ of solvent evaporation, PhaF was injected with a Hamilton syringe into the subphase (PBS buffer) beneath the polymer monolayer at a final concentration of $0.18 \mu \mathrm{M}$. The increase of surface pressure was recorded as a function of time $\left(\Delta \pi_{\mathrm{t}}\right)$, until a stable surface pressure was reached, and the microscopic modifications were traced by BAM. The effect of the composition of the monolayer on the adsorption kinetics of PhaF was demonstrated through the injection of PhaF under PLGA monolayers ${ }^{30}$ at an initial $\pi$ of $10 \mathrm{mN} / \mathrm{min}$, following the protocol described for PHOHHx. For all the experiments, the same volume injected was extracted from the subphase to avoid a volumedependent change in $\pi$. To discard artifact results from the injection protocol, we performed a control experiment where blank solution (PBS) was injected (data not shown).

Brewster Angle Microscopy (BAM). BAM measurements of pure and mixed films were carried out at the $A-W$ interface using a Langmuir trough equipped with an Ellipsometer Accurion Nanofilm EP3 (EP3, Accurion, Gottingen, Germany). The instrument was equipped with $658 \mathrm{~nm}$ class IIIB laser source and a high performance CCD camera $(1392 \times 1040$ pixel $)$. Images were taken simultaneously during the $\pi-A$ isotherm experiments with a resolution limit of $1 \mu \mathrm{m}$.

Infrared Measurements of PhaF in Solution. Measurement of the protein vibration spectrum in solution was carried out by Infrared
(IR) spectroscopy by attenuated total reflection (ATR-IR) using a FT-IR Tensor 27 system with an ATR crystal (Bruker Optik GmbH, Ettlingen Germany). Drops with three different concentrations of the protein in PBS $(0.1,0.5$, and $1.3 \mathrm{mg} / \mathrm{mL})$ were placed on the ATR crystal and the liquid was pressed on the crystal with a hollow pistil. Spectra were obtained at ambient temperature in the spectral range of $1200-1800 \mathrm{~cm}^{-1}$ at a resolution of $2 \mathrm{~cm}^{-1}$. An average of 64 cycles were used to increase signal-to-noise ratio. Spectra analysis was performed with OPUS software (version 7.5, Bruker Optik GmbH, Ettlingen Germany). The spectrum of the pure protein in solution (PBS) was obtained by subtracting the $0.1 \mathrm{mg} / \mathrm{mL}$ spectrum from the $1.3 \mathrm{mg} / \mathrm{mL}$ spectrum. By this procedure, most of the signal from proteins adsorbing to the ATR crystal is removed.

In situ PM-IRRAS. Infrared reflection-absorption spectroscopy (IRRAS) was used to determine the molecular conformation and orientation of the films. A polarization-modulation (PM) technique, PM-IRRAS, was applied to remove the vibrational and rotational bands of water. The IRRAS set up consisted of a KSV NIMA PMIRRAS spectrometer coupled to a Langmuir trough where the IRbeam was focused onto the A-W surface. FTIR spectra were acquired from 800 to $4000 \mathrm{~cm}^{-1}$ using s- and p-polarized light at an angle of incidence of $74^{\circ}$. Typically, 2500 scans were averaged.

The differential reflectivity spectrum $S$ is calculated from the collected difference $(\Delta R)$ and sum spectra $(\Sigma R)$ of the detected intensities of the p- and s-polarized light as $S=\frac{\Delta R}{\Sigma R}=\frac{R_{\mathrm{s}}-R_{\mathrm{p}}}{R_{\mathrm{s}}+R_{\mathrm{p}}}$. To obtain the spectrum of the film adsorbing to the $\mathrm{A}-\mathrm{W}$ interface, the sample spectrum is normalized with respect to the spectrum of the bare A-W interface $S_{0}$ with $S_{\text {film }}=\frac{S-S_{0}}{S_{0}}$. In the experiments with spread polymer films, these were compressed to a desired area per molecule, the barriers were then stopped and the IRRA spectra were recorded. In the adsorption experiments, the acquisition of the IRRA spectra started directly after the injection of the protein into the subphase. The PM-IRRAS measurements were performed twice. The biggest measurement error in IRRA spectra processing is normally obtained from the absorption-signal to baseline-noise ratio, resulting in false signal interpretation. To solve this problem, 3 background spectra were recorded and subtracted from the sample spectrum independently and only signals detected in all spectra were considered.

\section{RESULTS AND DISCUSSION}

Surface Behavior of Pure PhaF Monolayers. One of the most remarkable features of $\mathrm{PhaF}$ is its surface activity, induced by the segregation of polar residues from the hydrophobic ones on both sides of its $\mathrm{N}$-terminal $\alpha$-helix. ${ }^{26}$ The maximum surface pressure $\left(\pi_{\max }\right)$ of increasing amounts of PhaF in two different chemical environments, its saturating concentration at the $\mathrm{A}-\mathrm{W}$ interface and the effect of spreading (Langmuir monolayer) or injecting (adsorption Gibbs monolayer) the protein at the aqueous solution is presented in Figure 1. When PhaF was spread in increments at the $\mathrm{A}-\mathrm{W}$ interface, it showed greater surface activity on PBS than on water, reaching a maximum $\pi$ of $\sim 22 \mathrm{mN} / \mathrm{m}$. This could be explained by the high ionic strength of PBS (salting out effect), ${ }^{41,42}$ or by its $\mathrm{pH}$ being closer to the isoelectric point of $\mathrm{PhaF}=10$, which favors proteins surface activity. ${ }^{43}$ Upon spreading low concentrations of protein on the water surface, a rather high increase of the surface pressure was observed, confirming PhaF as a highly surface active protein. A pseudoplateau was observed at $\pi=$ $16-17 \mathrm{mN} / \mathrm{m}$, probably due to a reorientation of the molecules at the interface (see structural characterization below). Since direct spreading of the protein at the $A-W$ interface can be considered as a rather harsh method that might cause conformational changes, Gibbs layer formation upon injecting of the protein into the subphase was evaluated 


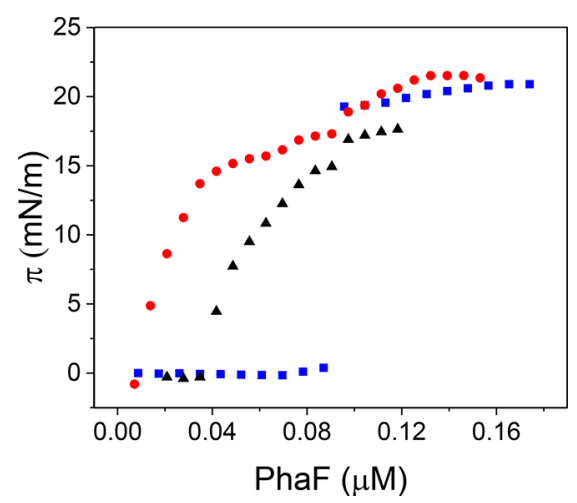

Figure 1. Surface activity of $\mathrm{PhaF}$ as a function of protein concentration. Each point in the curves corresponds to the maximal value of the surface pressure $(\pi)$ reached after protein addition. PhaF molar concentration $(\mu \mathrm{M})$ spread on water, $\mathrm{pH} 5.5$ (triangles) or PBS, pH 7.4 (circles). Protein injected into PBS subphase (squares).

as an alternative method to produce PhaF monolayers. Therefore, increasing amounts of PhaF were injected into PBS and were allowed to reach a stable surface pressure. The minimum concentration required to observe an increase of the surface pressure for Gibbs layers was higher by a factor of 10 when comparing to spreading of the protein solution at the A$\mathrm{W}$ interface $(0.10$ vs $0.01 \mu \mathrm{M})$, suggesting that the adsorption of the protein at the interface during spreading was irreversible. Interestingly, Gibbs layers did not show a plateau at $\sim 16 \mathrm{mN}$ / $\mathrm{m}$. Regardless of the formation mechanism, an equilibrium was established at $\sim 22 \mathrm{mN} / \mathrm{m}$ and a protein concentration $0.16-$ $0.18 \mu \mathrm{M}$ was sufficient to reach a saturation of the surface. This equilibrium is comparable to our previous observation under dynamic conditions (stirring the subphase). ${ }^{23}$

Phase Behavior and Morphology of PhaF Monolayers. A comparative study of spread and adsorbed monolayers of $\mathrm{PhaF}$ at the $\mathrm{A}-\mathrm{W}$ interface was performed with $\pi-A$ isotherms and $\pi$-t adsorption kinetics. These measurements were combined with in situ BAM and PMIRRAS to study morphological and structural features of the monolayers (Figure 2). During the compression of the PhaF Langmuir monolayer ( $\pi-A$ isotherm) a steady increase of the surface pressure starting from $1 \mathrm{mN} / \mathrm{m}$ with $C_{s}^{-1}$ of $60 \mathrm{mN} / \mathrm{m}$ was observed (Figure 2A). Two distinct transition points, which appeared as two minimum values in the $\mathrm{Cs}^{1-}$ isotherm, were detected between $\sim 16$ and $22 \mathrm{mN} / \mathrm{m}$. This gradual slope or "accordion" configuration may be an effect of repulsive forces along compression, conformational changes or mechanical distortion as it has been reported for other proteins. ${ }^{44,45}$ Based on our observations from the IRRAS spectrum (see below), the first minimum is attributed to a $\mathrm{PhaF}$ reorientation at the $\mathrm{A}-\mathrm{W}$ interface. We noted that the maximum surface pressure that can be obtained via adsorption from the subphase is about $22 \mathrm{mN} / \mathrm{m}$ (Figure 1 and Figure 2B), which is identified with a densely covered interface. Therefore, the second transition around this surface pressure indicates collapse or multilayer formation. BAM images of the Langmuir monolayer are shown in Figure 2C. Despite the pseudoplateau in the isotherm, only a homogeneous phase with no sudden change in intensity was present during compression up to 22 $\mathrm{mN} / \mathrm{m}$, at the resolution scale of the microscope $(1 \mu \mathrm{m})$. The morphology of films at higher $\pi$ was almost identical, except for the formation of some structures "folds" with different brightness (arrow in image e). The adsorption of PhaF at the $\mathrm{A}-\mathrm{W}$ interface $(\pi-t$ isotherm) was studied following the increase in surface pressure after injection of a single protein portion $(0.18 \mu \mathrm{M})$ without any external mechanical force (Figure $2 \mathrm{~B}$ ). Adsorption of $\mathrm{PhaF}$ comprised a considerable lag time, followed by a sudden increase in $\pi$ after $30 \mathrm{~min}$ (gas phase to liquid phase transition) and a gradual saturation of the interface at a maximal surface pressure of $21 \pm 1 \mathrm{mN} / \mathrm{m}$. No changes in morphology were observed in BAM, forming homogeneous layers similar to $a-d$ in Figure 2C. It is worth to mention that the adsorption isotherm of $\mathrm{PhaF}$ was identical at 21 and $37^{\circ} \mathrm{C}$ (Figure S3). Our results indicate that despite the
A)

B)

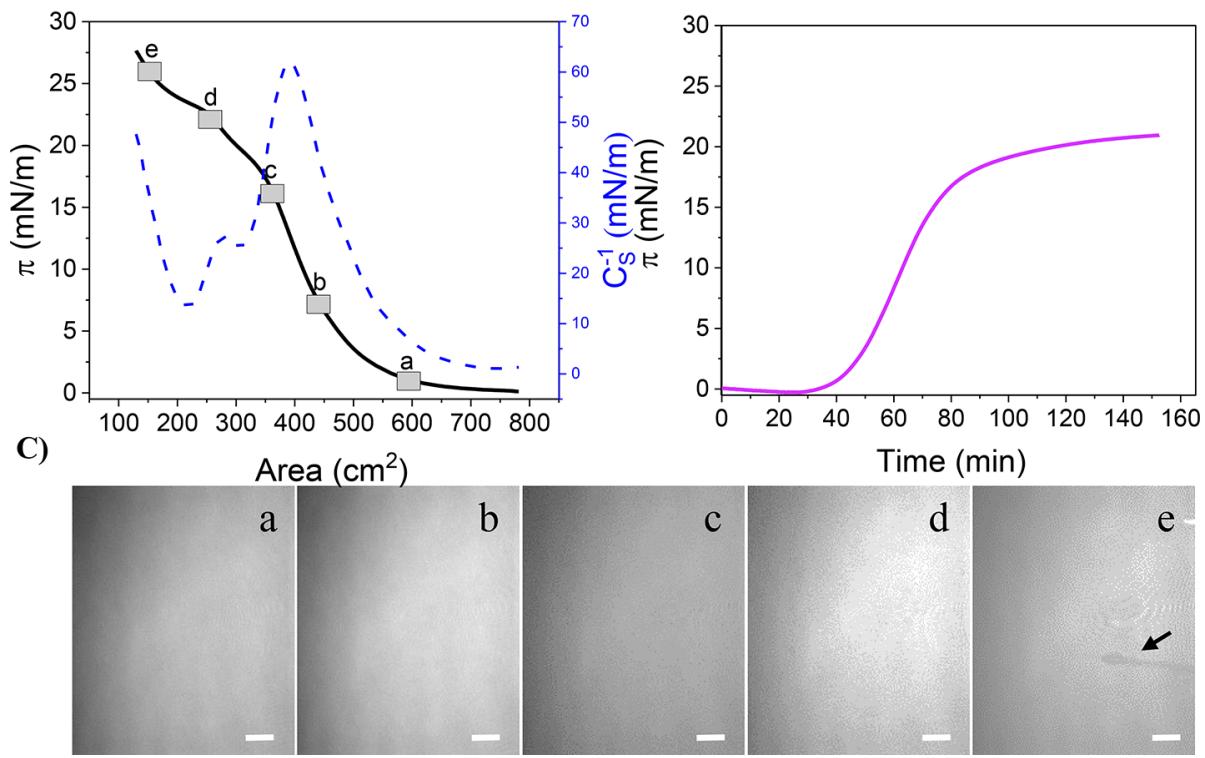

Figure 2. PhaF monolayers at the air-water (PBS) interface. (A) Surface pressure-area isotherm $(\pi-A$, solid line) and compressibility modulus $\left(C_{s}^{-1}\right.$, dotted line) of PhaF $(0.013 \mu \mathrm{M})$ spread on PBS. (B) Surface adsorption isotherm of PhaF $(0.18 \mu \mathrm{M})$ in a surface-area/volume ratio of 0.8 $\mathrm{cm}^{-1}$. (C) BAM images of PhaF monolayer at different surface pressures (a-e in $\pi-A$ curve). Scale bar $=50 \mu \mathrm{m}$. 
A)
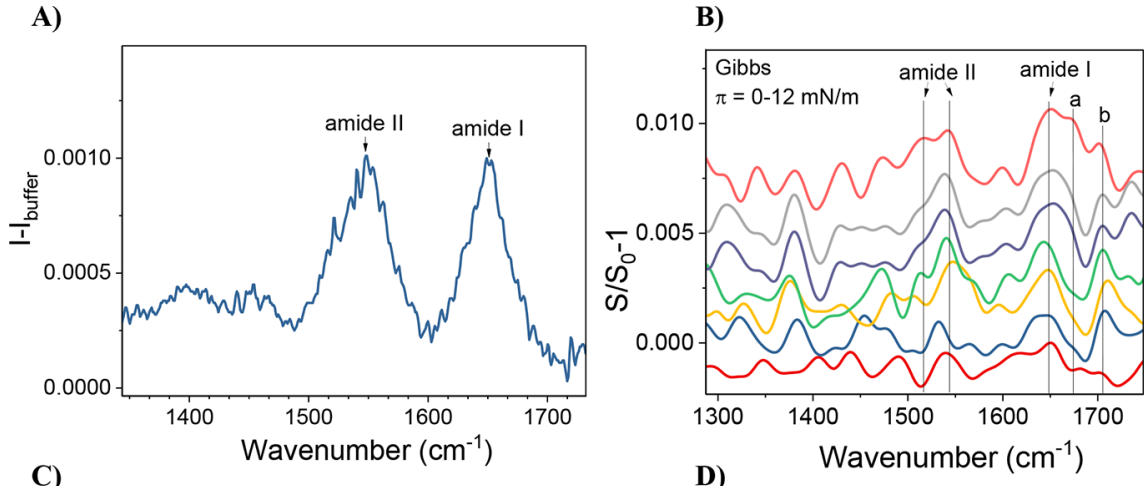

C)
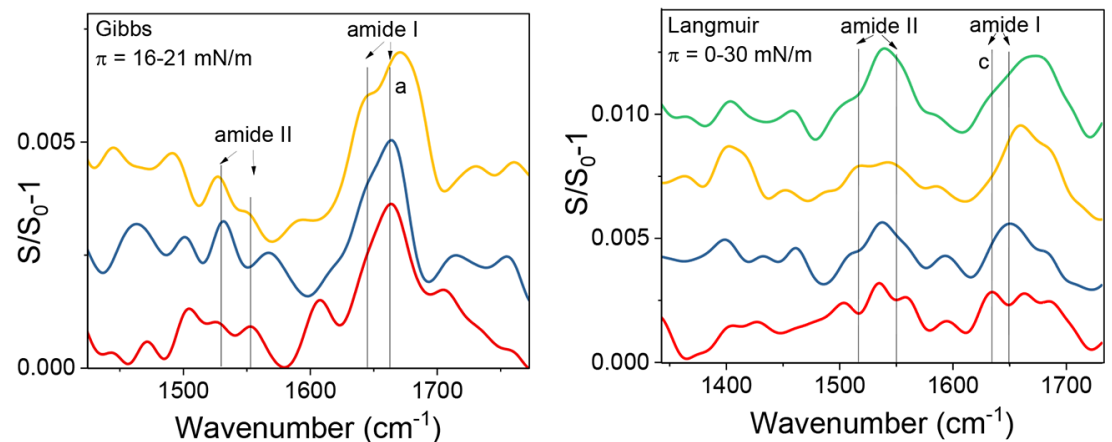

Figure 3. (A) IR spectrum of PhaF in PBS buffer. (B) PM-IRRAS spectra of PhaF at the A-W interface (Gibbs monolayers). From bottom to top: background spectrum, $\pi=0, \pi=1, \pi=2, \pi=5, \pi=8$, and $\pi=12 \mathrm{mN} / \mathrm{m}$. Vertical lines a, $\mathrm{b}=$ carboxylic acid side groups vibration. (C) PMIRRAS spectra of PhaF Gibbs monolayers at higher $\pi$. From bottom to top: $\pi=16, \pi=18$, and $\pi=21 \mathrm{mN} / \mathrm{m}$. Vertical line a carboxylic acid side groups vibration. (D) PM-IRRAS spectra of PhaF at the A-W interface (Langmuir monolayers). From top to bottom: $\pi=0, \pi=12.5, \pi=23$, and $\pi=30 \mathrm{mN} / \mathrm{m}$. Vertical line $\mathrm{c}=$ peak at $1630 \mathrm{~cm}^{-1}$ assigned to $\beta$-sheets. Spectra of the replicate measurements agreed qualitatively.

methodology use for PhaF monolayer formation, $22 \mathrm{mN} / \mathrm{m}$ is the maximum surface pressure to which PhaF may be compressed before it becomes unstable.

Conformation and Orientation of PhaF at Different Environments. Since the adsorption of protein monolayers at the $\mathrm{A}-\mathrm{W}$ interface could also lead to conformational changes, the infrared spectrum of $\mathrm{PhaF}$ was measured in solution in order to study the conformation of the protein in its native environment (Figure 3A). The spectrum in Figure 3A shows that the amide I and the amide II bands of the protein are centered at 1650 and $1546 \mathrm{~cm}^{-1}$ (with shoulder at $1520 \mathrm{~cm}^{-1}$ ), respectively. The amide I band at $1650 \mathrm{~cm}^{-1}$ in PBS buffer is typical for $\alpha$-helical structure, but can also contain contributions from random coil sections that have a similar amide I band position as $\alpha$-helices $\left(1644 \mathrm{~cm}^{-1}\right) .{ }^{46}$ This result agrees very well with the expected high $\alpha$-helical content of PhaF. ${ }^{26}$ The peak intensity ratio is unexpected, since the ratio of amide I to amide II for $\alpha$-helical proteins in solution is about $2 .^{47}$ Here, the amide II peak may overlap with vibrations from carboxylic acid side groups in the range from 1550 to 1580 $\mathrm{cm}^{-1}{ }^{48}$ Furthermore, the spectrum was recorded on an ATR crystal which leads to an overestimation of amide II intensity relative to amide $\mathrm{I}^{49}$

In situ PM-IRRAS spectra of PhaF monolayers show similar trends for layers prepared via adsorption from solution (Figure $3 \mathrm{~B}, \mathrm{C}$ ) and via compression (Figure 3D). At lower surface pressures (Figure $3 \mathrm{~B}$ ), the main component of amide $\mathrm{I}$ is at $1650 \mathrm{~cm}^{-1}$, in agreement with the $\alpha$-helical conformation found in solution, which also agrees with the amide II bands at 1515 to $1550 \mathrm{~cm}^{-1} .{ }^{50}$ At higher surface pressures (Figure $3 \mathrm{C}$ ), a shoulder of increasing intensity at about $1670 \mathrm{~cm}^{-1}$ (a) is observed for the amide I band. This shoulder could be attributed to an increasing degree of dehydration of the alpha helices, which is supported by a vibration of the carboxylic acid side groups at $1715 \mathrm{~cm}^{-1}(\mathrm{~b})$. Since deprotonation is expected in PBS, the side groups have to be at least partly exposed to air. A shoulder at $1630 \mathrm{~cm}^{-1}$ (c) in the amide I band of spread monolayers (Figure 3D) indicates the presence of a small content of $\beta$-sheets, supporting that injecting is a more gentle method of producing monolayers than spreading. The ratio of amide I to amide II intensity can be used to determine the orientation of the helices at the air-water interface. ${ }^{51} \mathrm{Up}$ to a surface pressure of $12 \mathrm{mN} / \mathrm{m}$, the ratio is about 1 , indicating a tilt angle of about $45^{\circ}$ with the surface normal, i.e. a random organization. Between 12 and $23 \mathrm{mN} / \mathrm{m}$, the ratio is much bigger than 1, suggesting that the helix axis are more or less parallel to the $\mathrm{A}-\mathrm{W}$ interface. Finally, at $30 \mathrm{mN} / \mathrm{m}$, the ratio approaches unity again, suggesting a random orientation. Since BAM suggests the layer collapses around $25 \mathrm{mN} / \mathrm{m}$, this result was expected. PM-IRRAS data allowed us to conclude that structural changes of PhaF were not significant when adsorbed from the subphase to the A-W interface. This is well-fitted to the dominant $\alpha$-helical organization, theoretically expected based on the three-dimensional structural model of PhaF. ${ }^{26}$ Converging, these results indicate an anisotropic orientation of the densely packed monolayer, preferentially oriented with the PhaF $\alpha$-helix axis parallel to the interface. Transitions between different oligomeric states have been proposed for phasins. ${ }^{26}$ At the $\mathrm{A}-\mathrm{W}$ interface $\mathrm{PhaF}$ oligomerization remains unveiled.

Adsorption of PhaF onto Copolyester Monolayers. Although phasins production and location are strictly associated with the PHA granules in bacteria, these proteins have been proven to bind to different hydrophobic substrates in vivo and in vitro. The use of the Langmuir technique as a 
A)

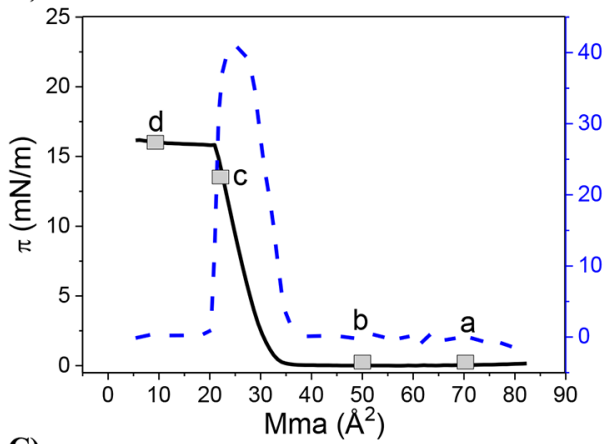

C)

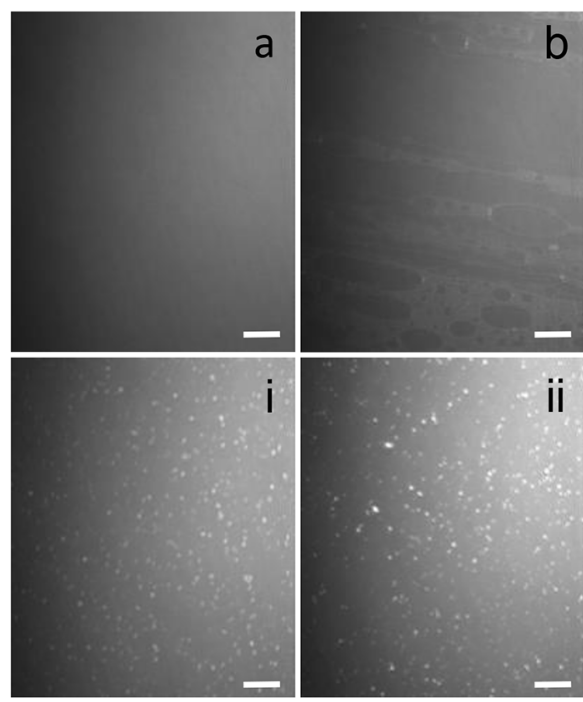

B)
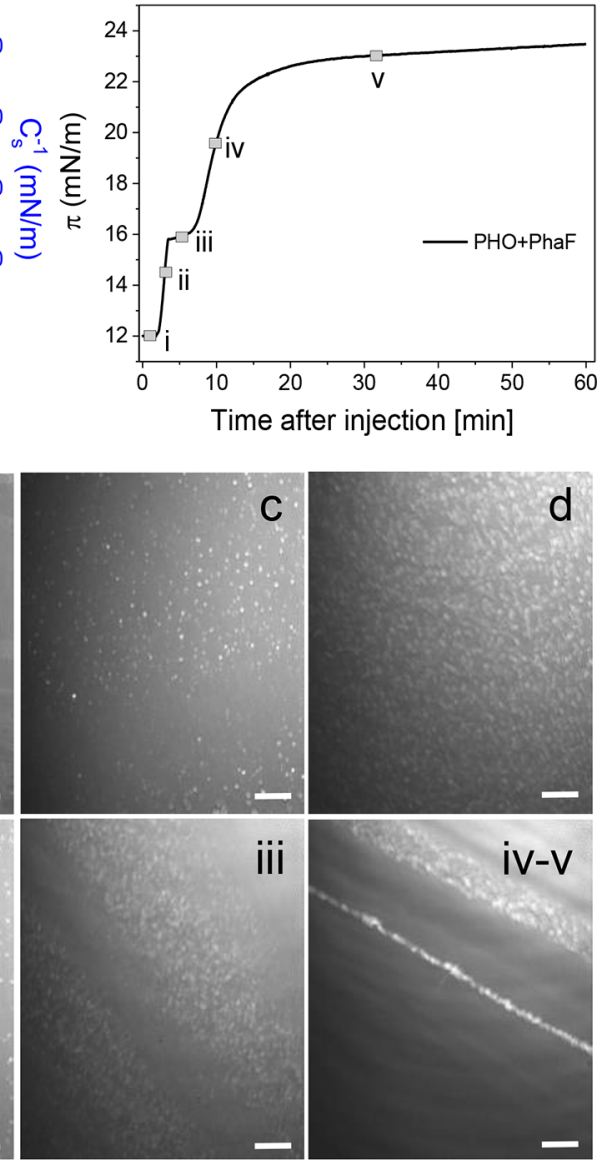

Figure 4. (A) Isotherm of surface pressure $(\pi)$ versus mean molecular area per monomer unit of PHOHHx (MMA). (B) Adsorption of PhaF into preformed PHOHHx monolayer at $12 \mathrm{mN} / \mathrm{m}$. (C) BAM images of PHOHHx at the A-W interface (a-d) or after PhaF injection under the polymer monolayer $(\mathrm{i}-\mathrm{v})$. Scale bar $=50 \mu \mathrm{m}$.

model system to study PhaF-polymer interaction was benchmarked by injecting PhaF in the subphase (PBS buffer) of preformed $\mathrm{PHOHHx}$ monolayers as described in Materials and Methods. This system was further extended to PLGA monolayers as a less hydrophobic substrate. To identify the ideal packing density of $\mathrm{PHOHHx}$ for these experiments, the $\pi-A$ isotherm for PHOHHx on PBS at $20 \pm 1{ }^{\circ} \mathrm{C}$ was first analyzed (Figure 4A). The sudden steep increase of the surface pressure is typical for polymers for which the $\mathrm{A}-\mathrm{W}$ interface is a bad or theta solvent. ${ }^{52}$ Collapse of the monolayer is observed at $\pi=15.7 \mathrm{mN} / \mathrm{m}$ and $21 \pm 1 \AA^{2}$ by a plateau with almost no upturn in the surface pressure even up to a MMA of $5 \AA^{2}$. Although the phases of PHA monolayer systems are not well characterized, the horizontal plateau observed at small molecular areas is similar to that referenced for poly $(3-R$ hydroxyundecenoate), (PHUE) ${ }^{53}$ BAM images of $\mathrm{PHOHHx}$ films in Figure 4C show that the surface is uniform for high MMA (a); however, at very low surface pressure $(\pi=0 \mathrm{mN}$ / $\mathrm{m})$, PHOHHx films exhibit dark regions of water covered by gaseous phase together with gray zones (b). These domains vanish during the monolayer compression and very small bright globular domains of roughly uniform size appear forming a mixed phase (c). An increase in number of the globular structures is observed when the film collapses at $\pi=$ $15.7 \mathrm{mN} / \mathrm{m}$ (d). These observations lead to the conclusion that at the collapse pressure of $15.7 \mathrm{mN} / \mathrm{m}$, further reduction of the MMA results in chains being squeezed out of the interface. This happens locally, leading to the micron sized globular structures observed in BAM. The small lateral size of these reversibly formed globular domains allows for their fast dissolution upon expansion of the layer, indicated by the low surface pressure-area hysteresis during compression-expansion cycles (Figure S4). Optical microscopy and AFM of PHOHHx films transferred to silicon wafers (Figure S5) confirmed the model of having isolated three-dimensional globuli embedded in a monolayer. The adsorption of $\mathrm{PhaF}$ to a highly packed film of $\mathrm{PHOHHx}(\pi=12 \mathrm{mN} / \mathrm{m})$ was monitored by means of increase in the system surface pressure at constant areas $(\Delta \pi(t))$ (Figure $4 \mathrm{~B}$ ). It has been previously demonstrated for lipid-protein systems that molecules penetrating lipid monolayers increase their surface pressure; while the surface pressure should essentially remain almost unchanged when proteins stay below the surface (e.g., interacting with lipid headgroups). ${ }^{54,55}$ Upon injection of the protein beneath the $\mathrm{PHOHHx}$ film, the $\pi$ of the interface increased from $\pi=12 \mathrm{mN} / \mathrm{m}$ to $\sim 16 \mathrm{mN} / \mathrm{m}$, owing the area occupied by PhaF molecules. After this point, the isotherm exhibited a semiplateau or "bend" that was absent when the protein adsorbed to the $\mathrm{A}-\mathrm{W}$ interface. This bend is consistent with the maximum surface pressure reached by pure $\mathrm{PHOHHx}$ monolayers after compression (Figure 4A) and may be linked to the PHOHHx monolayer collapse. ${ }^{56,57}$ Further insertion of PhaF increased the surface pressure slowly, until a maximum $\pi=\sim 22 \mathrm{mN} / \mathrm{m}$ was reached. In order to 


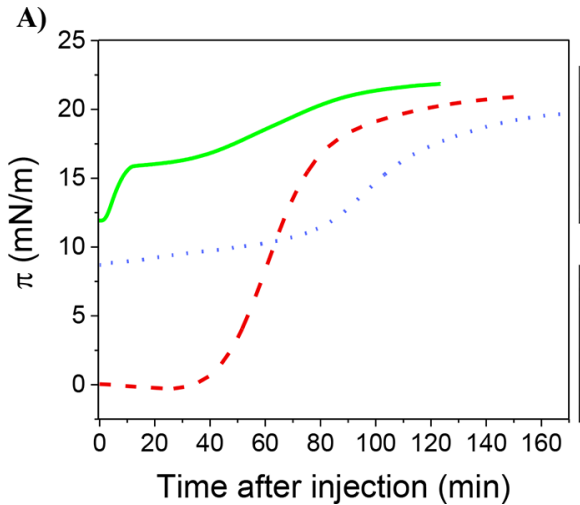

B)

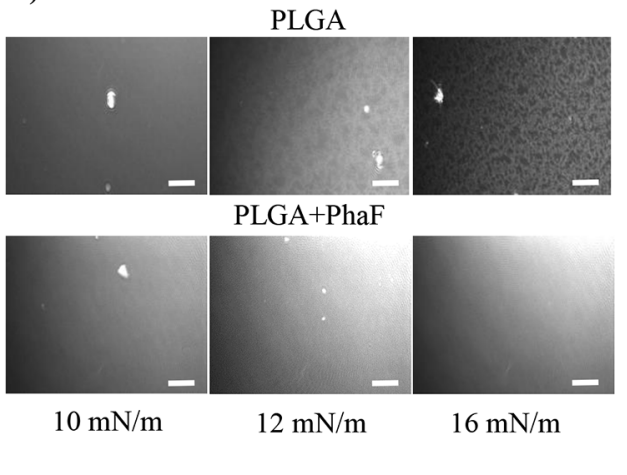

Figure 5. PhaF adsorption at hydrophobic/hydrophilic interfaces. (A) The $\Delta \pi(t)$ graph shows the increase of surface pressure after protein injection at the $\mathrm{A}-\mathrm{W}$ (dashed line), PHOHHx-water (solid line) and PLGA-water (dotted line) interfaces. (B) BAM images of PLGA and PLGA-PhaF mixed layers. Scale bar $=50 \mu \mathrm{m}$.
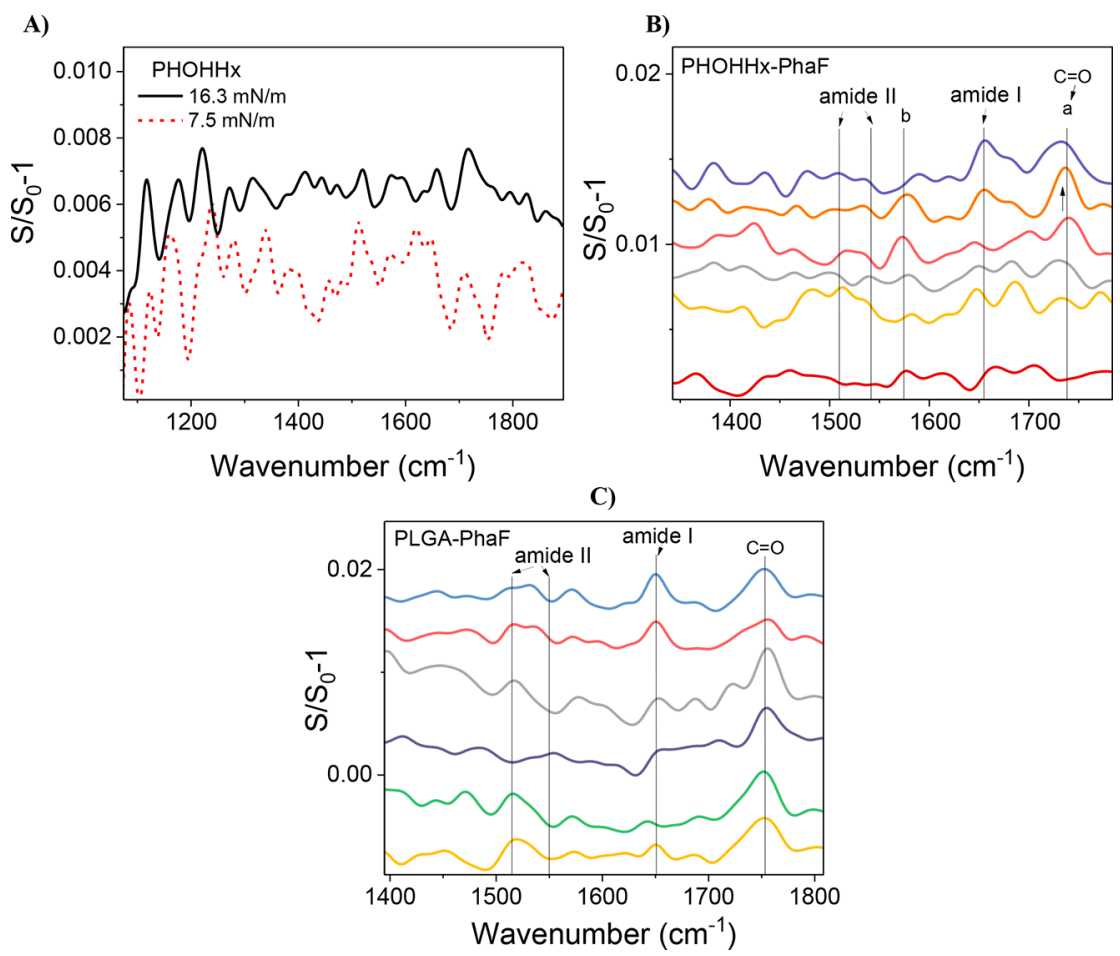

Figure 6. (A) PM-IRRAS spectra of PHOHHx at 7.5 and $16.3 \mathrm{mN} / \mathrm{m}$. (B) PM-IRRAS spectra of PhaF adsorption to the PHOHHx preformed monolayer. From bottom to top: PHOHHx background, $\pi=12, \pi=14.5, \pi=16, \pi=19$, and $\pi=21 \mathrm{mN} / \mathrm{m}$. Vertical lines a carbonyl bonds of PHA ester groups and $b=$ deprotonated carboxylate groups. C) Spectra of PhaF adsorption to the PLGA monolayer. From bottom to top: PLGA background, $\pi=9.4, \pi=10.2, \pi=13, \pi=19$, and $\pi=19.7 \mathrm{mN} / \mathrm{m}$. C $=\mathrm{O}$ peak = carbonyl bonds of PLGA ester groups. Spectra of the replicate measurements agreed qualitatively.

verify the influence of PhaF on the morphology of the PHOHHx monolayer, BAM images were recorded at different stages of protein adsorption (Figure 4C). At surface pressures below the polymer collapse, the BAM images of PhaF adsorbing to $\mathrm{PHOHHx}$ are similar to the ones of the pure polymer (i, ii), However, a phase-separation was observed above the bend, consisting of patches (bright thick stripes) of one component distributed between another (iii, iv, v). We conclude that the PhaF molecules reduce the available surface area for the $\mathrm{PHOHHx}$ chains, and the polymer is squeezed out of the layer when its collapse surface pressure is reached.

Adsorption of PhaF onto Synthetic Copolyester Monolayers. To address the effect of the substrate hydrophobicity on the adsorption of $\mathrm{PhaF}$, the same concentration of protein was injected under preformed PLGA monolayers (previously described in Schöne et al., 2015 ${ }^{29}$ ) at an initial $\pi=$ $10 \mathrm{mN} / \mathrm{m}$. The comparison of the three scenarios for protein adsorption (A-W, PHOHHx-water and PLGA-water) is shown in Figure 5. All the experiments were carried out in the same vessel, considering that PhaF velocity of adsorption might be diffusion limited. As shown in Figure 5, the kinetics of PhaF adsorption was markedly affected by the monolayer composition. However, the $\pi(t)$ curves cannot be translated directly into surface adsorption velocity curves. When PhaF inserts into preformed polymer films, the interface is already densely covered, and the insertion of additional molecules leads to an immediate increase of the surface pressure. In contrast, for the bare $\mathrm{A}-\mathrm{W}$ interface, a certain threshold 
surface concentration needs to be reached to observe an increase in the surface pressure, indicated by a lag time. Nevertheless, by comparing the slope of the $\pi(t)$ curve for PHOHHx at $t=0$ and the bare $\mathrm{A}-\mathrm{W}$ interface for $t=40 \mathrm{~min}$ (where a preformed PhaF layer exists), we found that the surface pressure increases at least as fast for preformed PHOHHx layers as for preformed PhaF layers. This holds true up to the collapse surface pressure of the polymer at $15.7 \mathrm{mN}$ / $\mathrm{m}$. Then, further insertion requires the displacement of PHOHHx chains into the third dimension, which slows down the insertion. On the other hand, the more hydrophilic polymer PLGA, for which the A-W interface is a good solvent, shows distinctly slower increase of the surface pressure than both $\mathrm{PHOHHx}$ and the bare $\mathrm{A}-\mathrm{W}$ interface, suggesting that PhaF molecules can barely penetrate the film. Furthermore, monolayers of PLGA-PhaF did not show the "bend" observed for $\mathrm{PHOHHx}-\mathrm{PhaF}$, confirming that its origin is the collapse of the PHOHHx monolayer.

When increasing concentrations of PLGA were spread on the bare $\mathrm{A}-\mathrm{W}$ interface, a pressure-induced aggregation (network-like structures) was observed by BAM (Figure 5B) at $\pi>11$, consistent with previous reports of PLGA Langmuir monolayers. ${ }^{30}$ Although PhaF increases the surface pressure of the PLGA system, the smooth surface observed upon injection of the protein (Figure 5B) implies that the presence of PhaF does not induce conformational changes in the polymer. This morphology was maintained up to $\sim 20 \mathrm{mN} / \mathrm{m}$. As pointed above, this could be an effect of the penetration of only few protein molecules into the PLGA monolayer, which causes lower mobility of the polymer chains compared to the increment of PLGA molecules on the interface. These results indicate that the protein determines the maximum surface pressure of protein-polymer films, as the surface pressure of the mixed films is the same as the PhaF equilibrium pressure. The injection of the blank solution into the subphase did not alter the initial pressure, neglecting a possible disruption of the monolayer (data not shown).

Structure and Orientation of PhaF in Mixed ProteinPolymer Layers. At the $\mathrm{A}-\mathrm{W}$ interface, the ester carbonyl bond of pure $\mathrm{PHOHHx}$, which is expected at $1741 \mathrm{~cm}^{-1}$, does not give rise to a PM-IRRAS signal (Figure 6A). This is attributed to the random walk of the polymer chains and the flexibility of the ester bond allowing for rotation around the COC bond, resulting in random orientation of the carbonyl groups. Hydrogen bonding between carbonyl oxygen atoms and water molecules could lead to an orientation of the ester bonds, but the layer is not expected to contain any solvent in the concentrated regime, which is realized for $\pi>2.4 \mathrm{mN} / \mathrm{m}$ (data not shown).

In contrast to water, PhaF was clearly able to enter the concentrated $\mathrm{PHOHHx}$ monolayer, as indicated by the peak at $1740 \mathrm{~cm}^{-1}$ (a) in Figure 6B. This absorption band is caused by the carbonyl bonds of the ester groups of PHOHHx. Thus, the interaction with $\mathrm{PhaF}$ causes a reorientation of the $\mathrm{PHOHHx}$ molecules, indicated by a preferentially parallel orientation of the carbonyl $\mathrm{C}=\mathrm{O}$ bond with respect to the $\mathrm{A}-\mathrm{W}$ interface. It has to be emphasized that this reorganization is not caused by reduction of the available area per repeat unit due to competitive adsorption of the proteins, since additional compression of the pure PHOHHx film to $16.3 \mathrm{mN} / \mathrm{m}$ and $13 \AA^{2}$ per repeat unit (Figure 6A) did not lead to a preferential orientation of the carbonyl bonds. The presence of $\mathrm{PhaF}$ in the layer is demonstrated by the amide I peak at $1656 \mathrm{~cm}^{-1}$ in conjunction with a weak and broad amide II signal between 1500 and $1550 \mathrm{~cm}^{-1}$. The intensity ratio suggests that the helices are oriented essentially parallel to the $\mathrm{A}-\mathrm{W}$ or polymer-water interface. ${ }^{51}$ The peak at $1575 \mathrm{~cm}^{-1}$ (b) is attributed to the vibrations of deprotonated carboxylate groups in the protein. When going from 19 to $21 \mathrm{mN} / \mathrm{m}$, this peak intensity decreases, while a shoulder appears at about 1715 $\mathrm{cm}^{-1}$. We suggest that this shift in intensity is caused by the protonation of acidic side groups, which indicates that the protein molecules become less hydrated at $21 \mathrm{mN} / \mathrm{m}$. Another strong peak at $1680 \mathrm{~cm}^{-1}$ should not be misread, since it can be caused by faulty removal of the water bending absorption as frequently observed when working with PM-IRRAS.

When comparing the PM-IRRAS spectra of PhaF adsorbing to PHOHHx and PLGA, we found similar peak positions. At the final surface pressure of the PLGA-PhaF mixed layer (Figure 6C), the position of amide I and amide II is at 1650 $\mathrm{cm}^{-1}$ and 1510 to $1550 \mathrm{~cm}^{-1}$, respectively, indicating $\alpha$-helical conformation. In analogy to $\mathrm{PHOHHx}$, the intensity ratio suggests that the main axis of the helices are oriented parallel to the $\mathrm{A}-\mathrm{W}$ or air-polymer interface. In contrast to PHOHHx, the PLGA molecules exhibit a preferentially parallel alignment of their carbonyl bonds with respect to the $A-W$ interface as demonstrated by the carbonyl stretching band at $1750 \mathrm{~cm}^{-1}$ in the absence of PhaF. This can be explained by hydrogen bonding between carbonyl oxygen and water. Since the polymer is in good solvent conditions the films contain a lot of water. ${ }^{29}$ The intensity of this carbonyl vibration does not change when the protein adsorbs. Interestingly, discernible amide vibrations are only observed at surface pressures above $19 \mathrm{mN} / \mathrm{m}$, indicating that only few protein molecules are causing the rise in surface pressure. Overall, our PM-IRRAS measurements confirm the importance of polymer hydration in determining protein adsorption to polymer materials, a finding that is also summarized in the "Whiteside rules". ${ }^{58}$ The more hydrophilic PLGA's strong interactions with water hinder the insertion of $\mathrm{PhaF}$ and stabilizes its conformation while the more hydrophobic $\mathrm{PHOHHx}$, which contains no water, adapts its conformation to the presence of the protein. Simulations suggest that substrate hydrophilicity also determines protein orientation and conformation. ${ }^{59}$ Our experiments showed that PhaF maintains its native conformation ( $\alpha$-helical) and flat orientation, independently of the hydrophobicity of the copolyester.

\section{CONCLUSIONS}

Alteration of surface properties of biomaterials to enable improved protein and cell interactions have largely relied on the implementation of chemical modifications, which for the most part are developed case-by-case and have demonstrated to be challenging. We selected phasin PhaF and its affinity toward PHA as a case study to promote an approach that allows a controlled physical immobilization of amphiphilic proteins to hydrophobic polyesters, reducing the limitation of substrates. Our work considers unexplored aspects of phasins physical adsorption, namely, the control of the conditions to preserve a stable coating and the molecular conformation of both species during the functionalization process. The adsorption of PhaF onto PHOHHx and PLGA Langmuir thin films was successfully followed in real time by means of the increment of the surface pressure $\Delta \pi(t)$, Brewster angle changes by BAM microscopy, and the shift in the molecular arrangement of the copolyester layers measured by PM-IRRAS. 
Stable mixed films of $\mathrm{PHOHHx}$ and PhaF are obtained up to $\pi$ of $\sim 16 \mathrm{mN} / \mathrm{m}$. From that point, the excess of PhaF induces the formation of separated domains and the collapse of the polymer layer. In the prospective of the assumption made in this work, the surface of granules being formed merely by proteins, these results let us conclude that elevated concentrations of PhaF function as a surfactant, separating PHA into "granules" in hydrophilic environments as occurs in the bacterial cytoplasm. The fact that PhaF binds to different hydrophobic polyesters in vitro, through relatively nonspecific interactions, as shown by the PhaF-mediated $\Delta \pi(t)$ of PLGA films, increases the number of polymer substrates that could be functionalized. However, our results highlight the importance of considering the hydrophobic nature of the polymer to be used. More strongly attractive interactions were observed between $\mathrm{PhaF}$ and $\mathrm{PHOHHx}$ (more hydrophobic copolyester) resulting in the adsorption of a much greater number of $\mathrm{PhaF}$ molecules.

We demonstrate that PhaF forms stable and robust monolayers, with an almost flat orientation of its $\alpha$-helix at the $\mathrm{A}-\mathrm{W}$ interface. This conformation was also adopted when adsorbing to PHOHHx and PLGA, ensuring the best exposure of the hydrophobic residues and providing a suitable coating strategy for functionalized polyester materials. In addition to serving as a conceptual-testing tool, the formation of PhaFalone films using the Langmuir technique is intended as a preparative method to fabricate coated surfaces, by transferring them onto various hydrophobic solid substrates while precisely controlling their thicknesses down to molecular dimensions. Future work might also consider using PhaF fusions with celldirecting elements or DNA molecules, to benefit from the bimodular structure of this phasin.

\section{ASSOCIATED CONTENT}

\section{S Supporting Information}

The Supporting Information is available free of charge on the ACS Publications website at DOI: 10.1021/acs.biomac.9b00069.

Secondary structure of PhaF, PHOHHx polymer characterization results, PhaF adsorption graph at different temperatures, compression-expansion isotherms of $\mathrm{PHOHHx}$, and morphology of $\mathrm{PHOHHx}$ films (PDF)

\section{AUTHOR INFORMATION}

\section{Corresponding Authors}

*A. Lendlein, e-mail: andreas.lendlein@hzg.de.

*M. A. Prieto, e-mail: auxi@cib.csic.es.

\section{ORCID $\odot$}

M. Auxiliadora Prieto: 0000-0002-8038-1223

Andreas Lendlein: 0000-0003-4126-4670

Notes

The authors declare no competing financial interest.

\section{ACKNOWLEDGMENTS}

The work was funded by the Helmholtz Graduate School Macromolecular Bioscience (no. VH-GS-503) and the Helmholtz Programme-oriented Funding. Additional funding was provided by the European Union's Horizon 2020 research and innovation program (no. 633962), Ministerio de Ciencia Innovación y Universidades (BIO2017-83448-R), and the PhD
Fellowship program of the Department of Science Technology and Innovation-Colciencias, Colombia. We acknowledge support of the publication fee by the CSIC Open Access Publication Support Initiative through its Unit of Information Resources for Research (URICI).

\section{REFERENCES}

(1) Cobo, I.; Li, M.; Sumerlin, B. S.; Perrier, S. Smart Hybrid Materials by Conjugation of Responsive Polymers to Biomacromolecules. Nat. Mater. 2015, 14, 143.

(2) Shu, J. Y.; Panganiban, B.; Xu, T. Peptide-Polymer Conjugates: From Fundamental Science to Application. Annu. Rev. Phys. Chem. 2013, 64 (1), 631-657.

(3) Haddad, T.; Noel, S.; Liberelle, B.; El Ayoubi, R.; Ajji, A.; De Crescenzo, G. Fabrication and Surface Modification of Poly Lactic Acid (PLA) Scaffolds with Epidermal Growth Factor for Neural Tissue Engineering. Biomatter. 2016, 6 (1), No. e1231276.

(4) Wang, T.; Yang, X.; Qi, X.; Jiang, C. Osteoinduction and Proliferation of Bone-Marrow Stromal Cells in Three-Dimensional Poly (E-Caprolactone)/ Hydroxyapatite/Collagen Scaffolds. J. Transl. Med. 2015, 13 (1), 152.

(5) Brown, J. H.; Das, P.; DiVito, M. D.; Ivancic, D.; Tan, L. P.; Wertheim, J. A. Nanofibrous Plga Electrospun Scaffolds Modified with Type I Collagen Influence Hepatocyte Function and Support Viability in Vitro. Acta Biomater. 2018, 73, 217-227.

(6) Maestro, B.; Sanz, J. M. Polyhydroxyalkanoate-Associated Phasins as Phylogenetically Heterogeneous Multipurpose Proteins. Microb. Biotechnol. 2017, 10 (6), 1323-1337.

(7) Mezzina, M. P.; Pettinari, M. J. Phasins, Multifaceted Polyhydroxyalkanoate Granule-Associated Proteins. Appl. Environ. Microbiol. 2016, 82 (17), 5060-5067.

(8) Liebergesell, M.; Schmidt, B.; Steinbüchel, A. Isolation and Identification of Granule-Associated Proteins Relevant for Poly(3Hydroxyalkanoic Acid) Biosynthesis in Chromatium Vinosum D. FEMS Microbiol. Lett. 1992, 99 (2-3), 227-232.

(9) Prieto, A.; Escapa, I. F.; Martinez, V.; Dinjaski, N.; Herencias, C.; de la Pena, F.; Tarazona, N.; Revelles, O. A Holistic View of Polyhydroxyalkanoate Metabolism in Pseudomonas Putida. Environ. Microbiol. 2016, 18 (2), 341-357.

(10) Wieczorek, R.; Pries, A.; Steinbüchel, A.; Mayer, F. Analysis of a 24-Kilodalton Protein Associated with the Polyhydroxyalkanoic Acid Granules in Alcaligenes eutrophus. J. Bacteriol. 1995, 177 (9), 24252435.

(11) Maehara, A.; Ueda, S.; Nakano, H.; Yamane, T. Analyses of a Polyhydroxyalkanoic Acid Granule-Associated 16-Kilodalton Protein and Its Putative Regulator in the PHA Locus of Paracoccus denitrificans. J. Bacteriol. 1999, 181 (9), 2914-2921.

(12) Neumann, L.; Spinozzi, F.; Sinibaldi, R.; Rustichelli, F.; Pötter, M.; Steinbüchel, A. Binding of the Major Phasin, PhaP1, from Ralstonia eutropha H16 to Poly(3-Hydroxybutyrate) Granules. J. Bacteriol. 2008, 190 (8), 2911-2919.

(13) Kuchta, K.; Chi, L.; Fuchs, H.; Pötter, M.; Steinbüchel, A. Studies on the Influence of Phasins on Accumulation and Degradation of PHB and Nanostructure of PHB Granules in Ralstonia eutropha H16. Biomacromolecules 2007, 8 (2), 657-662.

(14) Hänisch, J.; Wältermann, M.; Robenek, H.; Steinbüchel, A. The Ralstonia eutropha H16 Phasin PhaP1 Is Targeted to Intracellular Triacylglycerol Inclusions in Rhodococcus opacus Pd630 and Mycobacterium Smegmatis Mc2155, and Provides an Anchor to Target Other Proteins. Microbiology 2006, 152 (11), 3271-3280.

(15) Dong, Y.; Li, P.; Chen, C. B.; Wang, Z. H.; Ma, P.; Chen, G. Q. The Improvement of Fibroblast Growth on Hydrophobic Biopolyesters by Coating with Polyhydroxyalkanoate Granule Binding Protein PhaP Fused with Cell Adhesion Motif RGD. Biomaterials 2010, 31 (34), 8921-8930.

(16) Xie, H.; Li, J.; Li, L.; Dong, Y.; Chen, G. Q.; Chen, K. C. Enhanced Proliferation and Differentiation of Neural Stem Cells 
Grown on PHA Films Coated with Recombinant Fusion Proteins. Acta Biomater. 2013, 9 (8), 7845-7854.

(17) You, M.; Peng, G.; Li, J.; Ma, P.; Wang, Z.; Shu, W.; Peng, S.; Chen, G. Q. Chondrogenic Differentiation of Human Bone Marrow Mesenchymal Stem Cells on Polyhydroxyalkanoate (PHA) Scaffolds Coated with PHA Granule Binding Protein PhaP Fused with RGD Peptide. Biomaterials 2011, 32 (9), 2305-2313.

(18) Tallawi, M.; Rosellini, E.; Barbani, N.; Cascone, M. G.; Rai, R.; Saint-Pierre, G.; Boccaccini, A. R. Strategies for the Chemical and Biological Functionalization of Scaffolds for Cardiac Tissue Engineering: A Review. J. R. Soc., Interface 2015, 12 (108), 20150254.

(19) Park, H.; Radisic, M.; Lim, J. O.; Chang, B. H.; VunjakNovakovic, G. A Novel Composite Scaffold for Cardiac Tissue Engineering. In Vitro Cell. Dev. Biol.: Anim. 2005, 41 (7), 188-196.

(20) Giner-Casares, J. J.; Brezesinski, G.; Möhwald, H. Langmuir Monolayers as Unique Physical Models. Curr. Opin. Colloid Interface Sci. 2014, 19 (3), 176-182.

(21) Schöne, A. C.; Roch, T.; Schulz, B.; Lendlein, A. Evaluating Polymeric Biomaterial-Environment Interfaces by Langmuir Monolayer Techniques. J. R. Soc., Interface 2017, 14 (130), 20161028.

(22) Stefaniu, C.; Brezesinski, G.; Möhwald, H. Langmuir Monolayers as Models to Study Processes at Membrane Surfaces. Adv. Colloid Interface Sci. 2014, 208, 197-213.

(23) Mato, A.; Tarazona, N. A.; Hidalgo, A.; Cruz, A.; Jimenez, M.; Perez-Gil, J.; Prieto, M. A. Interfacial Activity of Phasin PhaF from Pseudomonas putida KT2440 at Hydrophobic-Hydrophilic Biointerfaces. Langmuir 2019, 35 (3), 678-686.

(24) Tarazona, N. A.; Maestro, B.; Revelles, O.; Sanz, J. M.; Prieto, M. A. Role of Leucine Zipper-Like Motifs in the Oligomerization of Pseudomonas putida Phasins. Biochim. Biophys. Acta, Gen. Subj. 2019, 1863 (2), 362-370.

(25) Galán, B.; Dinjaski, N.; Maestro, B.; de Eugenio, L. I.; Escapa, I. F.; Sanz, J. M.; García, J. L.; Prieto, M. A. Nucleoid-Associated PhaF Phasin Drives Intracellular Location and Segregation of Polyhydroxyalkanoate Granules in Pseudomonas putida KT2442. Mol. Microbiol. 2011, 79 (2), 402-418.

(26) Maestro, B.; Galán, B.; Alfonso, C.; Rivas, G.; Prieto, M. A.; Sanz, J. M. A New Family of Intrinsically Disordered Proteins: Structural Characterization of the Major Phasin PhaF from Pseudomonas putida KT2440. PLoS One 2013, 8 (2), e56904.

(27) Dinjaski, N.; Prieto, M. A. Swapping of Phasin Modules to Optimize the in Vivo Immobilization of Proteins to Medium-ChainLength Polyhydroxyalkanoate Granules in Pseudomonas putida. Biomacromolecules 2013, 14 (9), 3285-3293.

(28) Rai, R.; Keshavarz, T.; Roether, J. A.; Boccaccini, A. R.; Roy, I. Medium Chain Length Polyhydroxyalkanoates, Promising New Biomedical Materials for the Future. Mater. Sci. Eng., $R$ 2011, 72 (3), 29-47.

(29) Schöne, A. C.; Falkenhagen, S.; Travkova, O.; Schulz, B.; Kratz, K.; Lendlein, A. Influence of Intermediate Degradation Products on the Hydrolytic Degradation of Poly[(rac-lactide)-co-glycolide $]$ at the Air-Water Interface. Polym. Adv. Technol. 2015, 26 (12), 1402-1410.

(30) Schöne, A. C.; Richau, K.; Kratz, K.; Schulz, B.; Lendlein, A. Influence of Diurethane Linkers on the Langmuir Layer Behavior of Oligo[(rac-lactide)-co-glycolide]-Based Polyesterurethanes. Macromol. Rapid Commun. 2015, 36 (21), 1910-1915.

(31) Mach, H.; Middaugh, C. R. Measuring Protein Spectra in the Presence of Light Scattering. Biotechniques 1993, 15 (2), 240-242.

(32) Zinn, M.; Hany, R. Tailored Material Properties of Polyhydroxyalkanoates through Biosynthesis and Chemical Modification. Adv. Eng. Mater. 2005, 7 (5), 408-411.

(33) Dinjaski, N.; Fernandez-Gutierrez, M.; Selvam, S.; Parra-Ruiz, F. J.; Lehman, S. M.; San Roman, J.; Garcia, E.; Garcia, J. L.; Garcia, A. J.; Prieto, M. A. Phacos, a Functionalized Bacterial Polyester with Bactericidal Activity against Methicillin-Resistant Staphylococcus aureus. Biomaterials 2014, 35 (1), 14-24.

(34) Balk, M.; Behl, M.; Yang, J.; Li, Q.; Wischke, C.; Feng, Y.; Lendlein, A. Design of Polycationic Micelles by Self-Assembly of Polyethyleneimine Functionalized Oligo[( $\varepsilon$-Caprolactone $)$-co-glyco- lide] ABA Block Copolymers. Polym. Adv. Technol. 2017, 28 (10), $1278-1284$.

(35) Shen, X. W.; Shi, Z. Y.; Song, G.; Li, Z. J.; Chen, G. Q. Engineering of Polyhydroxyalkanoate (Pha) Synthase $\mathrm{PhaC} 2_{\mathrm{Ps}}$ of Pseudomonas stutzeri Via Site-Specific Mutation for Efficient Production of PHA Copolymers. Appl. Microbiol. Biotechnol. 2011, 91 (3), 655-665.

(36) Mathew, S.; Baudis, S.; Neffe, A. T.; Behl, M.; Wischke, C.; Lendlein, A. Effect of Diisocyanate Linkers on the Degradation Characteristics of Copolyester Urethanes as Potential Drug Carrier Matrices. Eur. J. Pharm. Biopharm. 2015, 95, 18-26.

(37) Tronin, A.; Dubrovsky, T.; De Nitti, C.; Gussoni, A.; Erokhin, V.; Nicolini, C. Langmuir-Blodgett Films of Immunoglobulines Igg. Ellipsometric Study of the Deposition Process and of Immunological Activity. Thin Solid Films 1994, 238 (1), 127-132.

(38) Dukhin, S.; Kretzschmar, G.; Miller, R. Thermodynamics and Macro-Kinetics of Adsorption. In Dynamics of Adsorption at Liquid Interfaces: Theory, Experiment, Application; Elsevier: Amsterdam, 1995; Vol. 1, pp 30-67.

(39) Rogalska, E.; Bilewicz, R.; Brigaud, T.; El Moujahid, C.; Foulard, G.; Portella, C.; Stébé, M.-J. Formation and Properties of Langmuir and Gibbs Monolayers: A Comparative Study Using Hydrogenated and Partially Fluorinated Amphiphilic Derivatives of Mannitol. Chem. Phys. Lipids 2000, 105 (1), 71-91.

(40) Graham, D. E.; Phillips, M. C. Proteins at Liquid Interfaces: Ii. Adsorption Isotherms. J. Colloid Interface Sci. 1979, 70 (3), 415-426.

(41) Yano, Y. F.; Uruga, T.; Tanida, H.; Terada, Y.; Yamada, H. Protein Salting out Observed at an Air-Water Interface. J. Phys. Chem. Lett. 2011, 2 (9), 995-999.

(42) Zhang, J. Protein-Protein Interactions in Salt Solutions. In Protein-Protein Interactions-Computational and Experimental Tools. IntechOpen, 2012.

(43) Dee, K. C.; Puleo, D. A.; Bizios, R. An Introduction to TissueBiomaterial Interactions; John Wiley \& Sons, 2003.

(44) Toimil, P.; Prieto, G.; Minones, J., Jr.; Trillo, J. M.; Sarmiento, F. Monolayer and Brewster Angle Microscopy Study of Human Serum Albumin-Dipalmitoyl Phosphatidyl Choline Mixtures at the Air-Water Interface. Colloids Surf., B 2012, 92, 64-73.

(45) Liu, W.; Li, S.; Wang, Z.; Yan, E. C.; Leblanc, R. M. Characterization of Surface-Active Biofilm Protein Bsla in SelfAssembling Langmuir Monolayer at the Air-Water Interface. Langmuir 2017, 33 (30), 7548-7555.

(46) Castano, S.; Blaudez, D.; Desbat, B.; Dufourcq, J.; Wróblewski, H. Secondary Structure of Spiralin in Solution, at the Air/Water Interface, and in Interaction with Lipid Monolayers. Biochim. Biophys. Acta, Biomembr. 2002, 1562 (1), 45-56.

(47) Venyaminov, S. Y.; Kalnin, N. N. Quantitative Ir Spectrophotometry of Peptide Compounds in Water $\left(\mathrm{H}_{2} \mathrm{O}\right)$ Solutions. Ii. Amide Absorption Bands of Polypeptides and Fibrous Proteins in A-, B-, and Random Coil Conformations. Biopolymers 1990, 30 (13-14), 12591271.

(48) Barth, A. The Infrared Absorption of Amino Acid Side Chains. Prog. Biophys. Mol. Biol. 2000, 74 (3), 141-173.

(49) Wilcox, K. E.; Blanch, E. W.; Doig, A. J. Determination of Protein Secondary Structure from Infrared Spectra Using Partial Least-Squares Regression. Biochemistry 2016, 55 (27), 3794-3802.

(50) Goormaghtigh, E.; Cabiaux, V.; Ruysschaert, J. M. Determination of Soluble and Membrane Protein Structure by Fourier Transform Infrared Spectroscopy. Iii. Secondary Structures. Subcell. Biochem. 1994, 23, 405-450.

(51) Castano, S.; Desbat, B.; Laguerre, M.; Dufourcq, J. Structure, Orientation and Affinity for Interfaces and Lipids of Ideally Amphipathic Lytic Likj(I = 2j) Peptides. Biochim. Biophys. Acta, Biomembr. 1999, 1416 (1), 176-194.

(52) Maestro, A.; Ortega, F.; Rubio, R. G.; Rubio, M. A.; Kragel, J.; Miller, R. Rheology of Poly(Methyl Methacrylate) Langmuir Monolayers: Percolation Transition to a Soft Glasslike System. J. Chem. Phys. 2011, 134 (10), 104704. 
(53) Jagoda, A.; Ketikidis, P.; Zinn, M.; Meier, W.; Kita-Tokarczyk, $\mathrm{K}$. Interactions of Biodegradable Poly([R]-3-Hydroxy-10-Undecenoate) with 1,2-Dioleoyl-Sn-Glycero-3-Phosphocholine Lipid: A Monolayer Study. Langmuir 2011, 27 (17), 10878-10885.

(54) Kanintronkul, Y.; Srikhirin, T.; Angsuthanasombat, C.; Kerdcharoen, T. Insertion Behavior of the Bacillus thuringiensis Cry4ba Insecticidal Protein into Lipid Monolayers. Arch. Biochem. Biophys. 2005, 442 (2), 180-186.

(55) Blume, A.; Kerth, A. Peptide and Protein Binding to Lipid Monolayers Studied by FT-IRRA Spectroscopy. Biochim. Biophys. Acta, Biomembr. 2013, 1828 (10), 2294-2305.

(56) Garg, S.; Swaminathan, V.; Dhavala, S.; Kiebish, M. A.; Sarangarajan, R.; Narain, N. R. Coq10 Selective Miscibility and Penetration into Lipid Monolayers with Lower Lateral Packing Density. Biochim. Biophys. Acta, Biomembr. 2017, 1859 (7), 11731179.

(57) Dynarowicz-Łątka, P.; Kita, K. Molecular Interaction in Mixed Monolayers at the Air/Water Interface. Adv. Colloid Interface Sci. 1999, 79 (1), 1-17.

(58) Wei, Q.; Becherer, T.; Angioletti-Uberti, S.; Dzubiella, J.; Wischke, C.; Neffe, A. T.; Lendlein, A.; Ballauff, M.; Haag, R. Protein Interactions with Polymer Coatings and Biomaterials. Angew. Chem., Int. Ed. 2014, 53 (31), 8004-8031.

(59) Quan, X.; Liu, J.; Zhou, J. Multiscale Modeling and Simulations of Protein Adsorption: Progresses and Perspectives. Curr. Opin. Colloid Interface Sci. 2019, 41, 74-85. 